\title{
Level of selected heavy metals in some commercially available cosmetic products in Dar es Salaam, Tanzania
}

\author{
Monica Mbaraka Ndoile* \\ Chemistry Department, College of Natural and Applied Sciences, \\ University of Dar es Salaam, PO Box 35061, Dar es Salaam, Tanzania. E \\ mail: monimgumba@gmail.com
}

\begin{abstract}
The study was conducted in order to assess heavy metal content in some commercially available cosmetics products that are manufactured in United Kingdom (UK), United States of America (USA), India and the Peoples Republic of China (PRC) and sold in Dar es Salaam, Tanzania. Face creams, beauty soaps, lipsticks and body lotions from the mentioned countries were purchased from local markets in Dar es Salaam and analytical procedures were employed to determine the contents of lead $(\mathrm{Pb})$, cadmium $(\mathrm{Cd})$ and copper $(\mathrm{Cu})$ using Flame Atomic Absorption Spectrometry (FAAS). The results showed that lipstick samples contained the highest $\mathrm{Pb}$ at $23.36 \mu \mathrm{g} / \mathrm{g}, \mathrm{Cd}$ at $23.30 \mu \mathrm{g} / \mathrm{g}$ and $\mathrm{Cu}$ at $22.91 \mu \mathrm{g} / \mathrm{g}$. The highest concentrations in the beauty soap samples showed $21.99 \mu \mathrm{g} / \mathrm{g} \mathrm{Pb}$, $0.98 \mu \mathrm{g} / \mathrm{g} \mathrm{Cd}$ and $18.8 \mu \mathrm{g} / \mathrm{g} \mathrm{Cu}$. Face cream samples contained the least contents of $\mathrm{Pb}$ at $6.52 \mu \mathrm{g} / \mathrm{g}, \mathrm{Cd}$ at $0.16 \mu \mathrm{g} / \mathrm{g}$, and $\mathrm{Cu}$ at $3.75 \mu \mathrm{g} / \mathrm{g}$. In body lotions, no $\mathrm{Pb}$ and $\mathrm{Cd}$ were detected; in contrast, the contents of $\mathrm{Cu}$ was high (up to $1.4 \mu \mathrm{g} / \mathrm{g}$ ). The products evaluated contained toxic heavy metals, though, not at an alarming concentration. Further research and analysis on the health risks of these products is proposed and extreme attention must be given to heavy metals during manufacture.
\end{abstract}

Keywords: Cosmetics; Heavy metals; FAAS; Lipsticks; Beauty Soaps; Face Creams

DOI: https://dx.doi.org/10.4314/ejst.v12i3.3

\section{INTRODUCTION}

In simple terms, a cosmetic product might be defined as a substance/preparation intended to be placed or applied to various

\footnotetext{
${ }^{*}$ Corresponding author: monimgumba@gmail.com
} 
external parts of the body to change appearance or body odor (Reed, 2007; Oyedeji et al., 2011). Therefore, cosmetics products contain mixtures of some surfactants, oils, and other additives that are necessary for long lasting and stable appearance. These products might be in the form of lipstick, lip gloss, powder, rouge, mascara, nail polish and others (Rao and Prathiba, 1998).

Millions of people use cosmetics under daily basis as part of routine body care since the beginning of civilization (Brown, 2013). Also, heavy metals are naturally found in the rocks, soils and water, thus, their existence in the cosmetics products is not surprising. External contact with cosmetics contaminated with heavy metals may lead to exposing oral cavity and mucosa, and therefore significant systemic exposure. Additionally, contaminated cosmetic products may produce skin effects like irritation, sensitization or photoreactions. With relatively significant uncontrolled exposure to contaminated cosmetic products, a thorough evaluation of their safety prior to marketing is thus of high priority.

Many dermatologists have considered cosmetic products more harmful than good, believed to contain ingredients linked to cancer, birth defects, developmental and reproductive harm (Groot et al., 1994); thus, the ban of coal tar colors, formaldehyde, glycol ethers, lead, mercury, parabens, phenylenediamine, phthalates containing cosmetics products.

Although various physical parameters may influence the absorption of heavy metals through skin, a consideration on the exposure through diet, medications and from the environment is also important (CDC, 2003). The use of cosmetics especially underarm cosmetics has been investigated as a possible cause of breast cancer (Lilley et al., 1988). It is the expectation that dermal exposure plays significant role in human body heavy metals contamination (Darbre, 2003). However, information on exposure to heavy metals through skin contact have been scanty (Sainio et al., 2000). The complete understanding and knowledge on the dermal-heavy metal interaction is of practical significance.

Many studies concerning heavy metal pollution determination in river waters, industrial effluents, city particulate matter, and roadside vegetables have been done in Tanzania (Mwegoha and 
Kihampa, 2010; Mohammed and Khamis, 2012; Ghanima, 2018). Some reports on the analysis of heavy metals contents in cosmetics exist, such as Nasirudeen and Amaechi (2015) who determined heavy metals contents in cosmetics available in Kaduna Metropolis, Nigeria. Others include Chauhan et al. (2010) and Mayildurai et al. (2015). In Tanzania, Mahugija (2018) reported levels of heavy metals in some cosmetic products sold in the country. However, Mahugija (2018) did not give details, and therefore, the present study was intended to provide a detailed assessment of heavy metal contents in various cosmetic products sold in Dar es Salaam.

\section{MATERIALS AND METHODS}

\section{Sample Collection}

Cosmetics product samples including face creams, beauty soaps, lipsticks and body lotions manufactured in UK, USA, PRC, and India were purchased from Mlimani city shopping mall, Kariakoo, Mwenge and Riverside shopping areas, in Dar es Salaam, Tanzania. A total of sixteen samples were collected (Table 1).

Table 1. Sample Categories, Names, Sources and Codes

\begin{tabular}{llll}
\hline $\begin{array}{l}\text { Sample } \\
\text { Category }\end{array}$ & Sample Name & $\begin{array}{l}\text { Manufacturer } \\
\text { country }\end{array}$ & $\begin{array}{l}\text { Sample } \\
\text { Code }\end{array}$ \\
\hline Beauty Soaps & Sandal Wood & PRC & A1 \\
& Tetmosol & India & A2 \\
& Dettol & UK & A3 \\
& Carambola & USA & A4 \\
Lipsticks & Apocalips & PRC & B1 \\
& Iman & India & B2 \\
& Milan & UK & B3 \\
Face Creams & Classic lipstick & USA & B4 \\
& Roushun whitening & PRC & C1 \\
& cream & & \\
& Dermasol cream & India & C2 \\
& Fair Lady Extra & UK & \\
& Whitening & & C4 \\
& Dagget \& Ramsdell & USA & D1 \\
cream & & D2 \\
Body Lotions & Roushun body lotion & PRC & D3 \\
& Vaseline lotion & India & D4 \\
& Fair Lady Body Milk & UK & \\
\hline Razac hand \& body & USA & \\
\hline lotion & & &
\end{tabular}




\section{Sample Preparation}

All glassware were thoroughly washed and soaked in $5 \% \mathrm{HNO}_{3}$ solution for $24 \mathrm{~h}$, followed by rinsing with deionized water before using them. Solid samples of cosmetics were oven dried $\left(105^{\circ} \mathrm{C}\right)$ until constant weight was obtained, and stored in desiccators. About $3.5 \mathrm{~g}$ of each of the dried cosmetic sample was placed in a porcelain crucible followed by dry-ashing in a muffle furnace for few hours $(\leq$ $550{ }^{\circ} \mathrm{C}$ ). The obtained ash samples were subjected to digestion using $1 \mathrm{M} \mathrm{HNO}_{3}$, on a hot plate evaporated to near dry in fume hood (Ayenimo et al., 2010), followed by cooling and filtering using Whatmann filter papers (Saeed et al., 2011). The solution was diluted to $100 \mathrm{~mL}$ in a calibrated flask.

Wet samples such as creams and lotions could not be conveniently prepared by dry-ashing method, thus, wet digestion was used (Saeed et al., 2011), where, a mixture of nitric acid and perchloric acid (4:1) were added to the test sample on a hot plate in fuming hood and evaporated to near dryness (Ayenimo et al., 2010). The temperature was slowly increased for about $2-3 \mathrm{~h}$, where brown or black color was obtained, the procedure was repeated by slowly adding the concentrated acid mixture and slowly heating until white fumes evolved marking the end of the digestion process (Theresa et al., 2011). These solutions were cooled, filtered and diluted to $100 \mathrm{~mL}$ in a calibrated flask. Blank samples were prepared in a similar way, except there was no sample addition during digestion process. The sample solutions were subsequently analyzed for lead, cadmium and copper by using FAAS (Thermo Fisher Scientific instrument, model iCE $3000 \mathrm{v} 1.3$ ).

\section{Sample Analysis}

Various methods could be used in the heavy metal determination including ICP-MS (Inductively Coupled Plasma-Mass Spectrometer) (Al-Dayel et al., 2011), SF-ICPMS (Sector FieldInductively Coupled Plasma Mass Spectrometer) (Bocca et al., 2007), Plasma Fission Spectrograph and inductively coupled plasma optical emission spectrometry (Parry and Eaton, 1991; Liu et al., 2009). However, FAAS is frequently used as an analytical method in determining heavy metal content in cosmetics (Amartey et al., 2011; Saeed et al., 2011). Thus, this study was carried out on Flame Atomic Absorption Spectrophotometer for $\mathrm{Pb}, \mathrm{Cu}$ and $\mathrm{Cd}$ 
determination. Calibration curves were prepared for each metal before sample analysis by running standard solutions at different concentrations. To correct reagent impurities, a reagent blank sample was analyzed and subtracted from the samples.

\section{Quality Control}

Recovery tests were performed by using selected cosmetic samples and distilled water for quality control experiments. For recovery tests, the recovery samples were spiked with standard solutions of the metals. These were processed following the same procedures used in cosmetics sample treatment. For recoveries determination, the amount of metals in the cosmetic samples was determined before spiking, and after spiking. Thus, percentage recoveries were established by using the formula:

$$
\% \text { Recoveries }=\frac{[\text { Spiked }]-[\text { Unspiked }]}{[\text { added }]} \times 100 \%
$$

Therefore, the recovery experiments were repeated for each metal, and results were used in determining the accuracy and precision of the method. Recoveries of $95-110 \%$ and precision relative standard deviation of $<5 \%$ were suitable.

\section{Statistics Analysis}

Total of sixteen cosmetics samples sold in Dar es Salaam were analyzed for heavy metal estimation and values obtained are presented in Table 2 as mean $\pm \mathrm{SD}$, with BDL representing Below Detection Limit. Data were analyzed by using one-way ANOVA (analysis of variance), and comparisons done by $t$-test with the GraphPad InStat software.

\section{Reagents and Standards}

All sample preparations were done by using double distilled water. Samples of cosmetics were prepared by analytical grade nitric acid (65\%, Sigma Aldrich) and perchloric acid (70-72\%, Sigma Aldrich). The certified standard stock solutions (1000 ppmmanufactured under ISO 9001 Quality Assurance system-Perkin Elmer) were used to prepare calibration standards ranging from 0.5 to $10 \mathrm{ppm}$ for each analyzed heavy metal. 


\section{RESULTS AND DISCUSSION}

In this study, an attempt was made to evaluate lead, copper and cadmium contents in face creams, lipsticks, body lotions and beauty soaps manufactured from India, Peoples Republic of China, United Kingdom and United States of America. The number of the selected cosmetics was sixteen (16), grouped into four, which are lipsticks, body lotions, creams and beauty soaps. In each category (group) products from the four manufacturing countries were obtained for analysis. Without neglecting the importance of analyzing body lotions, creams and soaps that have direct contact with human skin, it is considered important to analyze the amounts of heavy metals in lipsticks products since they have direct access to the body systemic (via ingestion). Upon analysis of concentrations of $\mathrm{Cu}, \mathrm{Pb}$ and $\mathrm{Cd}$ in the selected cosmetics, values lower than the detection limits were treated as Below Detection Limit (BDL) (Table 2).

Table 2. Mean Levels of $\mathrm{Pb}, \mathrm{Cd}$ and $\mathrm{Cu}$ (in $\mu \mathrm{g} / \mathrm{g}$ ) in the Sampled Cosmetics

\begin{tabular}{llllll}
\hline Sample & Code & Manufacturer & Pd & Cd & Cu \\
\hline Beauty Soaps & A1 & PRC & $22.0 \pm 0.009$ & $0.99 \pm 0.001$ & $18.8 \pm 0.005$ \\
& A2 & India & $8.7 \pm 0.005$ & $0.74 \pm 0.008$ & $0.4 \pm 0.005$ \\
& A3 & UK & BDL & $0.06 \pm 0.003$ & $0.1 \pm 0.004$ \\
Lipsticks & A4 & USA & $7.3 \pm 0.001$ & $0.16 \pm 0.005$ & $0.2 \pm 0.008$ \\
& B1 & PRC & $23.4 \pm 0.005$ & $23.3 \pm 0.008$ & $22.9 \pm 0.005$ \\
& B2 & India & $18.0 \pm 0.008$ & $17.0 \pm 0.008$ & $21.8 \pm 0.008$ \\
& B3 & UK & BDL & BDL & $1.9 \pm 0.005$ \\
Face Creams & B4 & USA & BDL & BDL & $2.4 \pm 0.005$ \\
& C1 & PRC & $6.5 \pm 0.05$ & $0.16 \pm 0.008$ & $3.8 \pm 0.001$ \\
& C2 & India & $1.1 \pm 0.009$ & BDL & $1.4 \pm 0.005$ \\
& C3 & UK & BDL & BDL & $0.7 \pm 0.009$ \\
Body Lotions & C4 & USA & BDL & BDL & $1.1 \pm 0.008$ \\
& D1 & PRC & BDL & BDL & $1.4 \pm 0.008$ \\
& D2 & India & BDL & BDL & $1.3 \pm 0.002$ \\
& D3 & UK & BDL & BDL & $0.7 \pm 0.006$ \\
& D4 & USA & BDL & BDL & $1.2 \pm 0.004$ \\
\hline
\end{tabular}

BDL = Below Detection Limit; UK = United Kingdom; USA = United States of America; $\mathrm{PRC}=$ Peoples Republic of China

Cosmetics have been used since the beginning of civilization by people regardless of their race, gender or age to beautify, or even modify/alter one's appearance. According to some studies, toxic metals occur in some cosmetics products (Chauhan et al., 2010; Faruruwa and Bartholomew, 2014). This implies the need to 
investigate the amounts of these toxic heavy metals. It has been proven that high doses of some heavy metals could be fatal, but also long-term exposure to low doses of these metals have been described to cause some types of cancer. For instance, the effects of exposures to higher concentrations of lead has been well documented, but it is of major concern that the possibility of continual exposure to even lower concentrations in cosmetic and other products may potentially pose health risks (Muhamad-Darus et al., 2011).

Generally, it can be observed from Table 2 and Figure 1 that there are substantial amounts of $\mathrm{Pb}$ and $\mathrm{Cd}$ in beauty soaps and lipsticks, and a little lesser in face creams, and the concentrations were below detection limits for $\mathrm{Pb}$, and $\mathrm{Cd}$ in body lotions. On the other hand, varying amounts of $\mathrm{Cu}$ have been observed across all cosmetic samples analyzed.

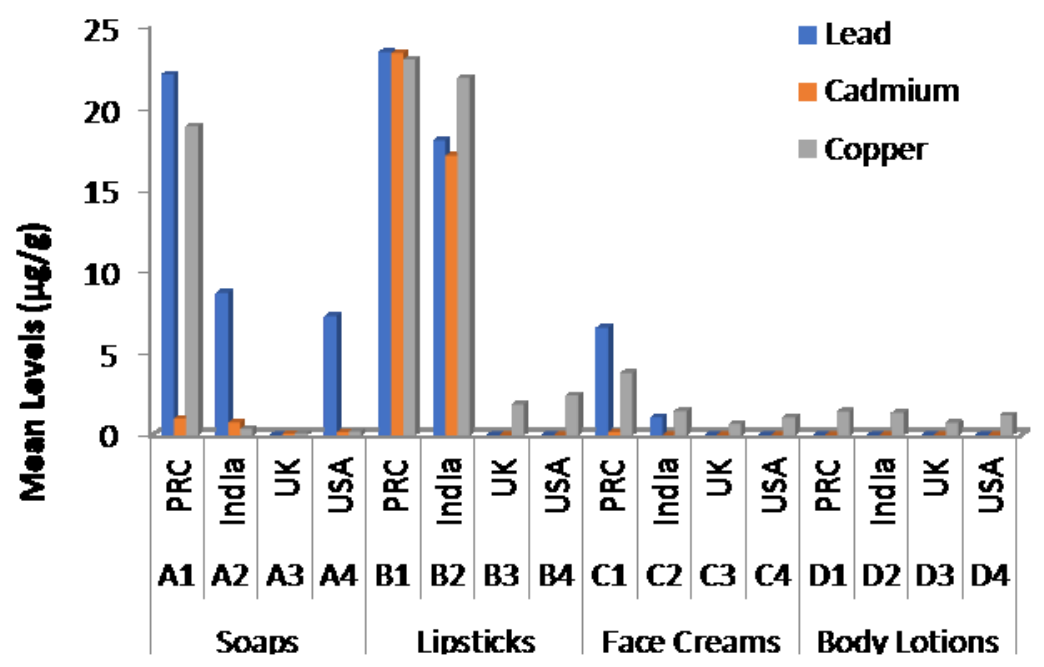

Figure 1. Heavy metal contents analyzed by FAAS in sampled cosmetics. 


\section{Concentrations of $\mathbf{P b}$}

\section{Lipsticks samples}

In this study, $\mathrm{Pb}$ concentrations in analyzed lipstick products ranged from $\mathrm{BDL}-23.4 \mu \mathrm{g} / \mathrm{g}$. The highest $\mathrm{Pb}$ concentrations were observed in lipstick samples from PRC $(23.4 \pm 0.005 \mu \mathrm{g} / \mathrm{g})$ followed by those from India $(18.0 \pm 0.008 \mu \mathrm{g} / \mathrm{g})$, and BDL amounts were observed in samples from UK and USA. Significant differences were observed in the concentrations of $\mathrm{Pb}$ among lipstick samples from PRC, India, UK and USA $\left(F_{2,23}=24.458, P<0.0001\right)$.

The results indicate that the amount of $\mathrm{Pb}$ in lipstick was about 9 times higher compared to previous study reports (Al-Saleh and AlEnazi, 2011). The report indicated the maximum $\mathrm{Pb}$ concentration in the lipsticks analyzed was $2.4 \mu \mathrm{g} / \mathrm{g}$. Lipsticks contained 0.286 to $6.234 \mu \mathrm{g} / \mathrm{g} \mathrm{Pb}$ according to Khalid et al. (2013) or 2.58 to 11.33 $\mu \mathrm{g} / \mathrm{g} \mathrm{Pb}$ according to Ullah et al. (2013).

\section{Beauty Soaps}

Lead concentrations in beauty soaps ranged from $0.07-18.8 \mu \mathrm{g} / \mathrm{g}$. The lowest $\mathrm{Pb}$ concentrations observed were in samples from UK, followed by those from USA. The concentrations are highest in beauty soaps samples from PRC followed by those from India. Oneway ANOVA indicated significant differences in the concentrations of $\mathrm{Pb}$ among beauty soaps samples from PRC, India, UK and USA $\left(F_{2,23}=11.814, \mathrm{p}=0.0001\right)$.

\section{Face creams and body lotions}

Some amounts of $\mathrm{Pb}$ were observed in face creams samples from PRC $(6.5 \pm 0.05 \mu \mathrm{g} / \mathrm{g})$, followed by those from India $(1.1 \pm 0.009$ $\mu \mathrm{g} / \mathrm{g}$ ), while BDL amounts were observed in samples from UK and USA. BDL amounts of $\mathrm{Pb}$ were observed in all body lotions samples studied.

\section{Concentrations of Cadmium}

The highest $\mathrm{Cd}$ concentrations in analyzed lipstick samples was observed to be $23.3 \pm 0.008 \mu \mathrm{g} / \mathrm{g}$ in samples from PRC followed by those from India $(17.0 \pm 0.008 \mu \mathrm{g} / \mathrm{g})$. One-way ANOVA showed significant differences in the concentrations of $\mathrm{Cd}$ among lipstick samples from PRC, India, UK and USA $\left(F_{2,23}=24.123, P<\right.$ 
0.0001). On the other hand, the concentrations were lower and BDL in beauty soaps, face creams and body lotions.

\section{Concentrations of Copper}

The concentrations of $\mathrm{Cu}$ in the analyzed cosmetic samples ranged from 22.9 to $0.1 \mu \mathrm{g} / \mathrm{g}$. The highest $\mathrm{Cu}$ concentrations were observed in lipstick samples from PRC $22.9 \pm 0.005 \mu \mathrm{g} / \mathrm{g}$ and India $21.8 \pm 0.008$ $\mu \mathrm{g} / \mathrm{g}$, as well as in beauty soaps from PRC $18.8 \pm 0.005 \mu \mathrm{g} / \mathrm{g}$. Cosmetic samples from UK and USA contained minimum amounts of $\mathrm{Cu}$. With an exception of lipsticks samples from PRC and India, and beauty soaps from PRC, the rest of the samples contained minimum amounts of $\mathrm{Cu}$. Statistical analyses indicated significant difference in $\mathrm{Cu}$ amounts among lipstick samples from UK, USA, $\mathrm{PRC}$ and India $\left(\mathrm{F}_{2,23}=16.934, P<0.0001\right)$.

Knowledge concerning the prolonged use of contaminated cosmetic products with their subsequent health effects are lacking among local populations. With the current type of culture that likes lipstick at very young age for women, coupled with the amounts of lead in the lipsticks studied possibilities are that upon ingestion, the levels of $\mathrm{Pb}$ might increase in the body (CSC, 2007). The high levels of $\mathrm{Pb}$ observed in lipstick products and beauty soaps may affect pregnant women and their babies. Highly contaminated eye product would be absorbed at $5-15 \%$ for adults and about $41 \%$ for children (Al-Dayel et al., 2011), suggesting the susceptibility of children. These heavy metals bind with the protein in the cell, thus, blocking its function and ultimately causing death of the respective cells, leading to multiple diseases (Shanker, 2008).

It is worth noting that toxic metals reported herein were not listed as ingredients on any of the products, thus, possibilities are that consumers as well as producers are unaware of the contaminants. It is clear that heavy metals in the products evaluated are unintentional contaminants. The contaminants might have gained access to the final cosmetic products when contaminated/poor quality raw materials are used. Therefore, manufacturers of cosmetics products are encouraged to remove these toxic impurities from the final products.

Although the levels of the toxic heavy metals in some of the studied cosmetic products is not alarming, exposure to low concentrations of 
these metals could be harmful to biological system if allowed to accumulate over time. Due to their longer half-life, these metals are known to accumulate in the human body organs. There are some reports that these metals can interfere with essential nutrients with similar oxidation states like calcium and zinc (Adepoju-Bello and Alabi, 2005).

\section{ACKNOWLEDGEMENTS}

Author would like to thank Dr. Ilomo (Chemistry Department, University of Dar es Salaam) for technical assistance during analyses.

\section{REFERENCES}

Adepoju-Bello, A.A and Alabi, O.M. (2005). Heavy metals: a review. The Nigeria Journal of Pharmacy 37: 41-45.

Al-Dayel, O., Hefne, J and Al-Ajyan, T. (2011). Human exposure to heavy metals from cosmetics. Oriental Journal of Chemistry 27 (1): 01-11.

Al-Saleh, I and Al-Enazi, S. (2011). Trace metals in lipsticks. Toxicology and Environmental Chemistry 93: 1149-1165.

Amartey, E.O., Asumadu-Sakvi, A.B., Adjei, C.A., Quashie, F.K., Duodu, G.O and Bentil, N.O. (2011). Determination of heavy metals concentration in hair pomades on the Ghanian market using atomic absorption spectrometry technique. British Journal of Pharmacology and Toxicology 2(4): 192-198.

Ayenimo, J.G., Yusuf, A.M., Adekule, A.S and Makinde, O.W. (2010). Heavy metal exposure from personal care product. Bulletin of Environmental Contamination Toxicology 84(1): 8-14.

Bocca, B., Forte, G., Petrucci, F and Cristaudo, A. (2007). Levels of nickel and other potentially allergenic metals in Ni-tested commercial body creams. Journal of Pharmaceutical Biomedical Analysis 44(5): 11971202.

Brown, V.J. (2013). Metals in lip products: A cause for concern. Environmental Health Perspectives 121(6): 196.

CDC, Centers for Disease Control and Prevention (2003). Second National Report on Human Exposure to Environmental Chemicals. Available from: http://www.cdc.gov/exposurereport/2nd

Chauhan, A.S., Bhadauria, R., Singh, A.K., Lodhi, S.S., Chaturvedi, D.K and Tomari, V.S. (2010) Determination of lead and cadmium in 
cosmetics products. Journal of Chemical and Pharmaceutical Research 2: $92-97$.

CSC, the Campaign for Safe Cosmetics (2007). A poison kiss: the problem of lead in lipsticks. Available from:

http://www.safecosmetics.org/about/reports.cfm

Darbre, P.D. (2003). Underarm cosmetic and breast cancer. Journal of Applied Toxicology 23(2): 89-95.

Faruruwa, M.D and Bartholomew, P.S. (2014). Study of Heavy Metals content in Facial Cosmetics obtained from open markets and super stores within Kaduna Metropolis. American Journal of Chemistry and Application 2: 27-33.

Ghanima, C. (2018). Heavy Metal Pollution Assessment along Msimbazi River, Tanzania. Journal of Scientific Research \& Reports 17(5): 1-8.

Groot, A.C.D., Nater, J.P and Weyland, J.W. (1994). Unwanted Effects of Cosmetics and Drugs Used in Dermatology, Third Ed. (issue 1). Elsevier.

Khalid, A., Bukhari, I., Riaz, M., Rehman, G., Ain, Qu., Bokhari, Th., Rasool, N., Zubair, M and Munir, S. (2013). Determination of lead, cadmium, chromium, and nickel in different brands of lipsticks. International Journal of Biology, Pharmacy and Allied Sciences 2(5): 1003-1009.

Lilley, S.G., Florence, T.M and Stauber, J.L. (1988). The use of sweat to monitor lead absorption through the skin. Science of the Total Environment 76: 267-278.

Liu, H., Chen, L.P., Ai, Y.W., Yang, X., Yu, Y.H., Zuo, Y.B and Fu, G.Y. (2009). Heavy metal contamination in soil alongside mountain railway in Sichuan China. Environmental Monitoring and Assessment 152: 2533.

Mahugija, J. A. M. (2018). Levels of heavy metals in drinking water, cosmetics and fruit juices from selected areas in Dar es Salaam, Tanzania. Tanzania Journal of Science 44(1): 1-11.

Mayildurai, R., Ramasubbu, A and Velmani, N. (2015). ICP - OES investigations of heavy metal contents in cosmetic products. Journal of Pharmacy Research 9(1): 27-30.

Muhamad-Darus, F., Nasir, R.A., Sumari, S.M., Ismail, Z.S and Omar, N.A. (2011). Nursery schools, Characterization of heavy metal content indoor dust. Asian Journal of Enviroment-Behaviour Studies, 2(6): 53-60.

Mwegoha, W.J.S and Kihampa, C. (2010). Heavy metal contamination in agricultural soils and water in Dar es Salaam city, Tanzania. African Journal of Environmental Science and Technology 4(11): 763-769.

Mohammed, N.K and Khamis, F.O. (2012). Assessment of heavy metal contamination in vegetables consumed in Zanzibars. Natural Science 4(8): 588-594. 
Nasirudeen, M.B and Amaechi, A.U. (2015). Spectrophotometric determination of heavy metals in cosmetics sourced from Kaduna Metropolis, Nigeria. Science World Journal 10(3): 1-5.

Oyedeji, F.O., Hassan, G.O and Deleke, B.B. (2011). Hydroquinone and heavy metal levels in cosmetics marketed in Nigria, Trends in Applied Sciences Research 6: 622-639.

Parry, C and Eaton, J. (1991). Kohl: a lead-hazardous eye makeup from the third world to the first world. Environmental Health Perspectives 94: 121-123.

Rao, N and Prathiba, S. (1998). Cosmetics and personal care products, Elsevier Inc: $380-382$.

Reed, S. (2007). Cosmetics and your health. USA Department of Health and Human Services: 22-25.

Shanker, A. K. (2008). Mode of action and toxicity of trace elements, in Trace elements as contaminants and nutrients: consequences in ecosystems and human health. In: Mode of action and toxicity of trace elements, pp.1882-1912 (Prasad, M.N.V. Ed.). John Wiley \& Sons, Inc.

Saeed, M., Muhammad, N and Khan, H. (2011). Assessment of heavy metal content of branded Pakistani herbal products. Tropical Journal of Pharmaceutical Research 10(4): 499-506

Sainio, E.L., Jolanki, R., Hakala, E and Kanerva, L. (2000). Metals and arsenic in eye shadows. Contact Dermatitis. 42(1): 5-10.

Theresa, O.C., Onebunne, O.C., Dorcas, W.A and Ajani, O.I. (2011). Potentially toxic metals exposure from body creams sold in Lagos, Nigeria. Researcher 3(1): 30-37.

Ullah, H., Noreen, S., Fozia., Rehman, A., Waseem, A., Zubair, S., Adnan, M and Ahmad, I. (2013). Comparative study of heavy metals content in cosmetic products of different countries marketed in Khyber Pakhtunkhwa, Pakistan. Arabian Journal of Chemistry 10(1): 10-18. 